Wei LIU, Hongzhong QI, Xintian LIU, Yansong WANG

\title{
Evaluation of regenerative braking based on single-pedal control for electric vehicles
}

(C) The Author(s) 2019. This article is published with open access at link.springer.com and journal.hep.com.cn

\begin{abstract}
More than 25\% of vehicle kinetic energy can be recycled under urban driving cycles. A single-pedal control strategy for regenerative braking is proposed to further enhance energy efficiency. Acceleration and deceleration are controlled by a single pedal, which alleviates driving intensity and prompts energy recovery. Regenerative braking is theoretically analyzed based on the construction of the single-pedal system, vehicle braking dynamics, and energy conservation law. The single-pedal control strategy is developed by considering daily driving conditions, and a single-pedal simulation model is established. Typical driving cycles are simulated to verify the effectiveness of the single-pedal control strategy. A dynamometer test is conducted to confirm the validity of the simulation model. Results show that using the single-pedal control strategy for electric vehicles can effectively improve the energy recovery rate and extend the driving range under the premise of ensuring safety while braking. The study lays a technical foundation for the optimization of regenerative braking systems and development of single-pedal control systems, which are conducive to the promotion and popularization of electric vehicles.
\end{abstract}

Keywords electric vehicle, single-pedal control regenerative braking, co-simulation, dynamometer test

\section{Introduction}

Although vehicles have provided convenience to humans,

Received April 17, 2019; accepted May 21, 2019

Wei LIU, Xintian LIU ( $₫)$, Yansong WANG

School of Mechanical and Automotive Engineering, Shanghai

University of Engineering Science, Shanghai 201620, China

E-mail: xintianster@gmail.com

Hongzhong QI

Automotive Engineering Institute, Guangzhou Automobile Group Co. Ltd., Guangzhou 511434, China they have also caused severe environmental issues and raised concerns regarding energy. The recent development of electric vehicles (EVs) has alleviated this problem [1]. One of the main factors that restrict the development of EVs is the limited driving range. An effective solution to this problem is maximizing the energy utilization efficiency of EVs to extend their driving range because EVs are limited by the current capacity of energy storage devices and electric driving systems. As a key technology for EVs, regenerative braking has been utilized in various types of EVs, hybrid EVs (HEVs), and plug-in HEVs [2,3]. The regenerative braking system based on single-pedal control was developed and applied to EVs to further improve mature conventional regenerative braking systems and their energy recovery rate.

Most vehicles are driven between downtowns and suburbs. Considering current traffic conditions, vehicles should be driven slowly, and brakes must be frequently applied [4]. Figure 1 shows the braking strength distribution for the major urban driving cycles (US06, NYCC and LA92 are marked in red, 10-15 MODE, FTP75, HWFET and UDDS are marked in green, NEDC and WLTP are

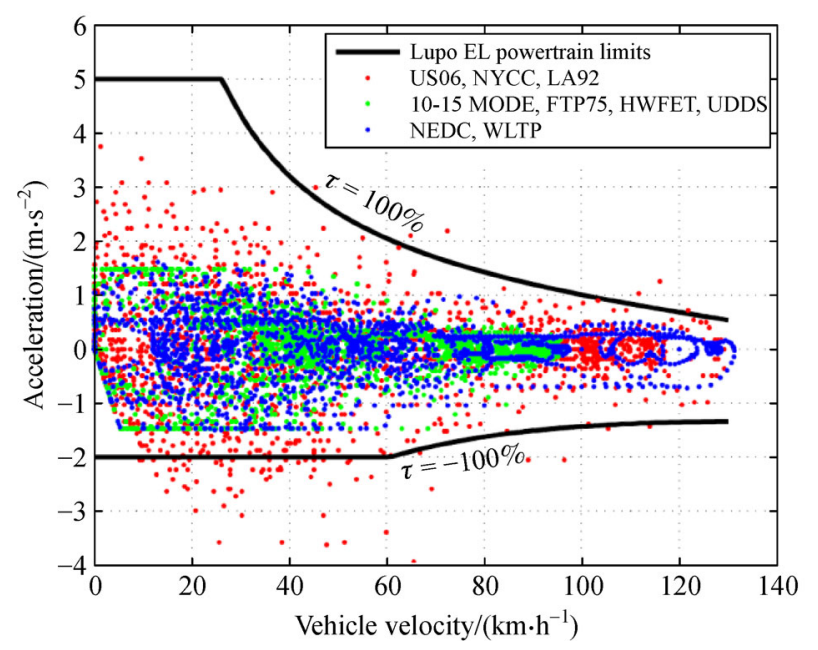

Fig. 1 Braking strength distribution of typical urban driving cycles. 
marked in blue), the bold black line is the powertrain limits of Lupo EL. As can be seen from the figure, the maximum braking strength of more than $90 \%$ driving cycles is less than 0.2 , and $74 \%$ of which is less than 0.1 . The braking force required in a low-intensity braking condition is also small so that the proportion of regenerative braking in the entire braking process can be enhanced, which is beneficial for energy recovery [5]. The energy generated during braking cannot be fully recovered, and a portion of it is lost in air as heat. A considerable amount of braking energy can be recovered while driving in cities [6].

International research has shown that $90 \%$ of daily driving can be achieved by a single pedal, and the reserved brake pedal is for emergency braking only [7]. This feature considerably reduces the driver's frequency of switching pedals, especially during traffic jams and downtown commute, and thus makes driving easy. In addition, single-pedal control can maximize the energy recovery rate and extend the driving range [8]. The BMW i3 is the first vehicle equipped with the single-pedal control system, which was introduced in 2012. Deceleration can be achieved by releasing the accelerator pedal, and the single pedal can carry out almost all of driving and braking as long as the driver maintains appropriate operation [9]. Another example is the Nissan Leaf, which features an e-pedal button. The driver can choose from a selection of driving modes according to the current traffic condition. For example, the traditional driving mode should be selected during high-speed, long-distance drive to help avoid foot fatigue caused by long-term deep pedaling on the accelerator pedal. The single-pedal driving mode should be selected when driving in crowded urban places because it considerably reduces the frequency of pedal switching and makes driving easy. Driving style is also crucial to vehicle energy efficiency and ride comfort. Aside from enhancing adaptation to various traffic conditions, the two driving modes also improve economic feasibility and driving performance [10-12]. The all-new Chevrolet Bolt is equipped with four driving modes. Specifically, two control modes that feature single-pedal and paddle control are available under Drive/Low. Drivers can flexibly choose from different driving modes depending on their driving needs, and this selection greatly enhances driving pleasure [13]. Driving on busy roads, the Bolt features a singlepedal control system with a mileage capacity that is approximately 5\% larger than that of vehicles using the conventional regenerative braking system. Major domestic auto corporations have introduced EVs with the singlepedal control system. The latest EVs, such as Geely Emgrand EV450, BAIC EU5, and JAC iEVA50, are equipped with the single-pedal control system. Notably, this system cannot completely replace the conventional brake pedal because mechanical braking is still necessary during emergencies.

The remainder of the paper is organized as follows. Section 2 theoretically analyzes single-pedal control based on the energy conservation law, vehicle braking dynamics, and regenerative braking system. A single-pedal control strategy is developed, and a single-pedal control model is established in Section 3. Co-simulation is conducted, and its results are evaluated in Section 4. A dynamometer test is performed, and its results are analyzed in Section 5. Section 6 provides the conclusions.

\section{Single-pedal control research foundation}

\subsection{Construction of the single-pedal system}

In the single-pedal control system, a conventional accelerator pedal is used to control motor torque. Driving and braking torques are positive and negative, respectively. The magnitude and direction of motor torque are related to single-pedal travel. A vehicle accelerates or decelerates when the driver steps on or releases the accelerator pedal, respectively. The single-pedal control system is usually applied in pure EVs or HEVs. As shown in Fig. 2, the single-pedal system combines the accelerator and brake

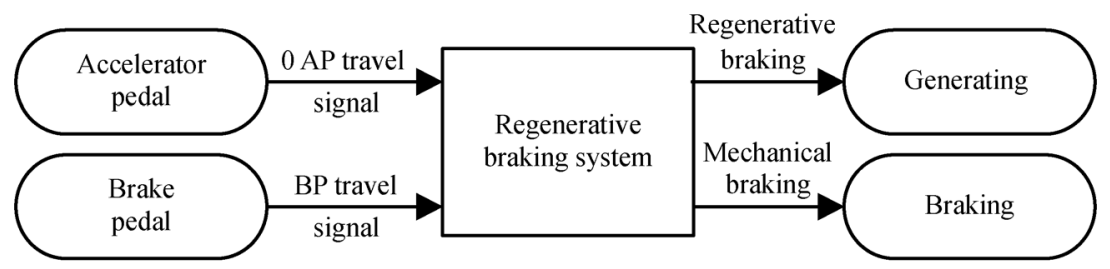

(a)

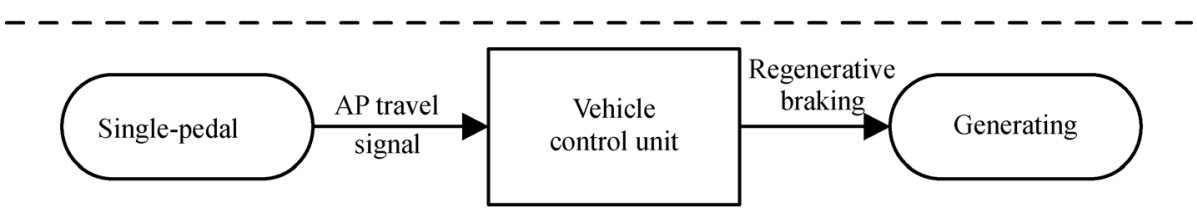

(b)

Fig. 2 Braking energy recovery system. (a) Conventional energy recovery; (b) single-pedal energy recovery. AP: Accelerator pedal; BP: Brake pedal. 
pedals, and regenerative braking is controlled by the accelerator pedal.

As shown in Fig. 3, the construction of the single-pedal system is identical to that of the traditional regenerative braking system. However, the single-pedal system requires less hardware adjustment, and most of the work is directed toward strategy development and software upgrade. Driving and regenerative braking torques are dynamically allocated by the vehicle control unit (VCU) according to vehicle velocity, accelerator pedal travel, and single-pedal control strategy. A motor control unit (MCU) controls the inverter to convert the motor from driving mode to generating mode. Most of the regenerative braking energy is fed back to the power battery for charging [14-16]. In certain emergency situations, the regenerative braking torque cannot meet the vehicle braking demand. The traditional mechanical braking system is still necessary and must work together with the regenerative braking system to ensure reliability and safety when braking [17].

\subsection{Theoretical analysis of regenerative braking}

Energy cannot be generated or dissipated. It can only be converted from one form to another or transferred from one object to another. The sum of energy is always the same. The law of energy conservation, one of the basic laws in nature, also applies to regenerative braking [18].

In the single-pedal mode, deceleration and braking are completely performed by the motor, and no mechanical brake system is involved. Total braking force $F_{\mathrm{b}}$ pertains to regenerative braking force $F_{\mathrm{rb}}$. Resistance $F_{\mathrm{d}}$ (flat road, regardless of slope resistance) during the regenerative braking process includes rolling resistance $F_{\mathrm{f}}$, air resistance $F_{\mathrm{w}}$, and regenerative braking force $F_{\mathrm{rb}}$.

$$
F_{\mathrm{d}}=m a=F_{\mathrm{f}}+F_{\mathrm{w}}+F_{\mathrm{rb}},
$$

where $m$ denotes the vehicle mass and $a$ represents the vehicle acceleration.

Overcoming the resistance when braking is necessary. The instantaneous braking power of EV $P_{\mathrm{d}}$ can be denoted by the equation

$$
P_{\mathrm{d}}=F_{\mathrm{d}} \cdot u=\left(F_{\mathrm{f}}+F_{\mathrm{w}}+F_{\mathrm{rb}}\right) \cdot u,
$$

where $u$ is the vehicle's velocity.

The total energy required to overcome braking force, $W_{\mathrm{d}}$, is as follows:

$$
\begin{aligned}
W_{\mathrm{d}} & =\int P_{\mathrm{d}} \mathrm{d} t=F_{\mathrm{f}} \int u \mathrm{~d} t+F_{\mathrm{w}} \int u \mathrm{~d} t+F_{\mathrm{rb}} \int u \mathrm{~d} t \\
& =F_{\mathrm{f}} \cdot S+F_{\mathrm{w}} \cdot S+F_{\mathrm{rb}} \cdot S \\
& =E_{\mathrm{f}}+E_{\mathrm{w}}+E_{\mathrm{rb}},
\end{aligned}
$$

where $S$ is the braking distance, $t$ is the time of driving or braking, $E_{\mathrm{f}}$ is the energy consumed to overcome rolling resistance, $E_{\mathrm{w}}$ is the energy consumed to overcome air resistance, and $E_{\mathrm{rb}}$ is the energy consumed to overcome the regenerative braking force.

The velocity when braking at initial time $t_{0}$ is assumed to be $u_{0}$, and the velocity at braking ending time $t_{1}$ is $u_{1}$. According to the kinetic energy theorem, the total energy consumed during the braking process, $\Delta E$, can be calculated as follows:

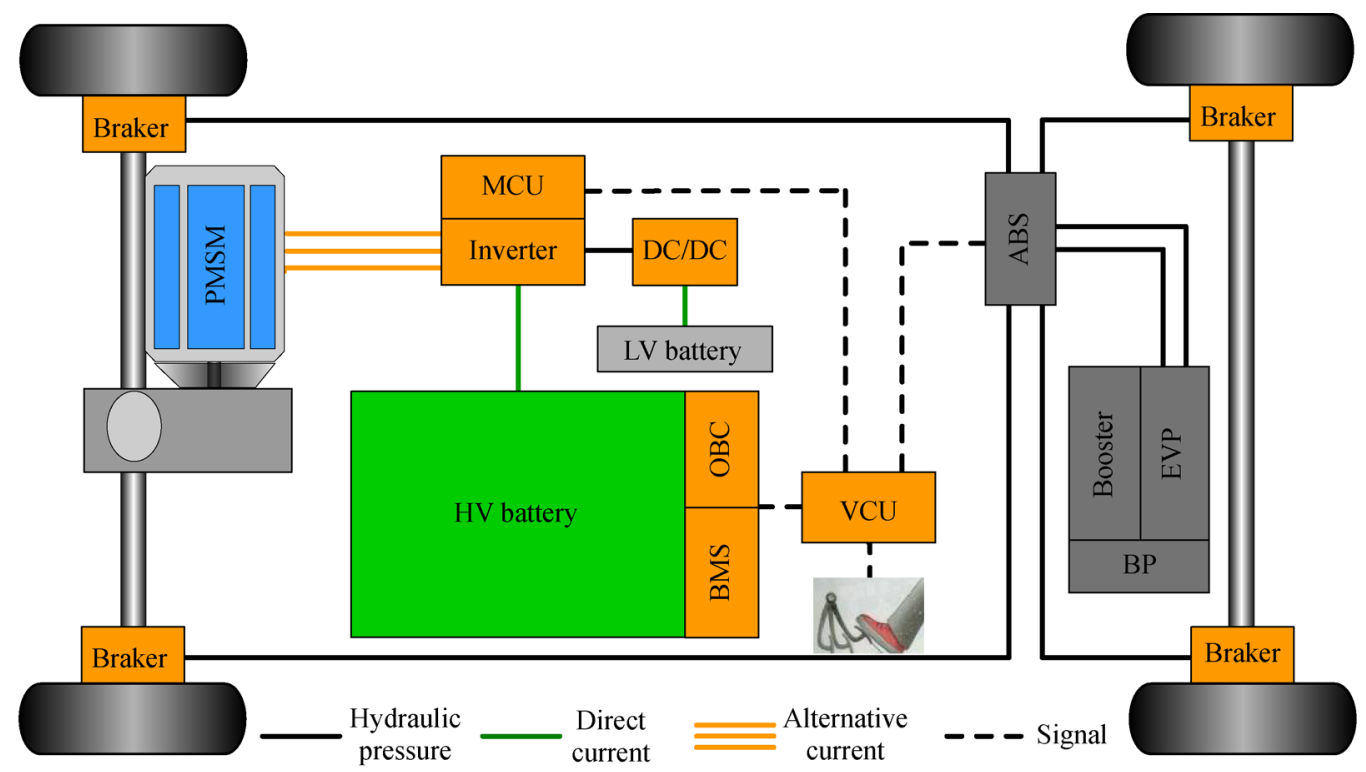

Fig. 3 Construction of the single-pedal control system. DC: Direct current; BP: Brake pedal; EVP: Electric vacuum pump; ABS: Antibrake system; OBC: On-board charger; BMS: Battery management system; PMSM: Permanent magnet synchronous motor; HV: High voltage; LV: Low voltage. 


$$
\Delta E=E_{0}-E_{1}=\frac{1}{2} m u_{0}^{2}-\frac{1}{2} m u_{1}^{2},
$$

where $E_{0}$ is the kinetic energy at the beginning of braking and $E_{1}$ is the kinetic energy at the end of braking.

According to the law of energy conservation, the energy consumed during the braking process of EVs is completely used to overcome resistance, which is denoted as follows:

$$
\Delta E=W_{\mathrm{d}}=E_{\mathrm{f}}+E_{\mathrm{w}}+E_{\mathrm{rb}} .
$$

The energy consumed to overcome the regenerative braking force during the braking process can be derived through

$$
E_{\mathrm{rb}}=\Delta E-E_{\mathrm{f}}-E_{\mathrm{w}} .
$$

In consideration of generating efficiency, the actual braking energy recovered, $E_{\text {gen }}$, can be expressed as follows:

$$
E_{\text {gen }}=E_{\mathrm{rb}} / \eta_{\text {gen }}
$$

where $\eta_{\text {gen }}$ is the generating efficiency.

\section{Single-pedal control strategy}

The traditional regenerative braking control strategy is relatively simple. Within a certain range, the regenerative braking torque is proportional to the brake pedal travel. When the energy recovery level is selected, the regenerative braking strength is fixed. Typically, the regenerative braking torque is set small to ensure drivability, which leading to lower energy recovery rate $[19,20]$. By contrast, the single-pedal control strategy is relatively complicated but highly aligned with ergonomics. Acceleration or deceleration can be achieved only when the driver steps on or releases the accelerator pedal, respectively. When the demand for deceleration is high, the brake pedal needs to be stepped on. Single-pedal control can reduce the frequency of pedal shifting, thereby providing the driver with improved driving experience. EVs equipped with the single-pedal control system have a high energy recovery rate, and their regenerative braking deceleration is large and controllable. In terms of hardware, the single pedal serves as the conventional accelerator pedal. In terms of software, single-pedal control can achieve the full function of the accelerator pedal and most of the functions of the brake pedal. Figure 4 shows the two control strategies.

\subsection{Driving condition analysis}

Recovery, coasting and acceleration in the single pedal mode correspond to negative torque, zero torque and positive torque of the motor, respectively. According to the calibration result of the BMW i3, single-pedal travel is allocated roughly according to recovery $(0 \%-30 \%)$, coasting (30\%-35\%), and acceleration (35\%-100\%), and it varies with vehicle velocity. Pedal travel allocation is shown in Table 1, where A, C, and $\mathrm{R}$ represent acceleration, coasting, and recovery, respectively.

As shown in Table 1, driving and braking conditions under single-pedal control can be divided into the following modes:

1) Acceleration

The brake pedal should be released, and the accelerator pedal must be lightly stepped on. If the accelerator pedal is greater than 0 , then the positive motor torque will become the output for acceleration. Accelerator pedal travel of $35 \%$ corresponds to the maximum velocity of $7 \mathrm{~km} / \mathrm{h}$. The corresponding maximum velocity increases linearly with pedal travel at the range of $0 \%-35 \%$. Acceleration under low velocity $(v \leqslant 7 \mathrm{~km} / \mathrm{h})$ replaces the creep function of conventional vehicles and mainly helps the vehicle start.

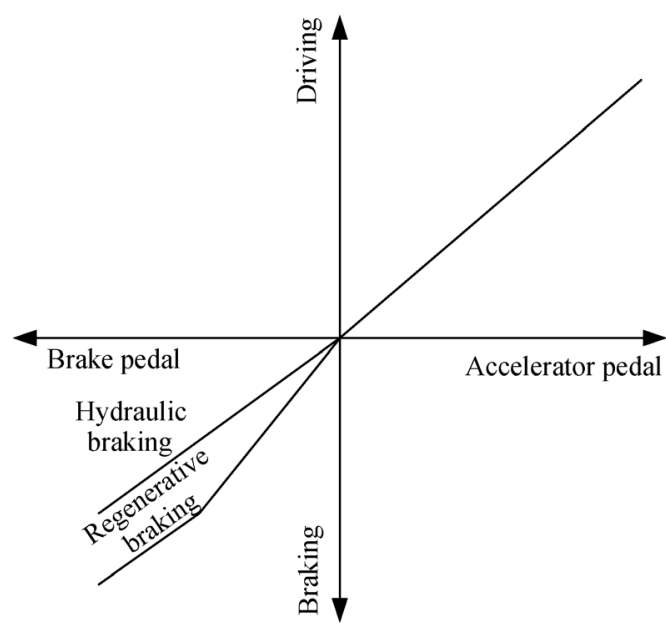

(a)

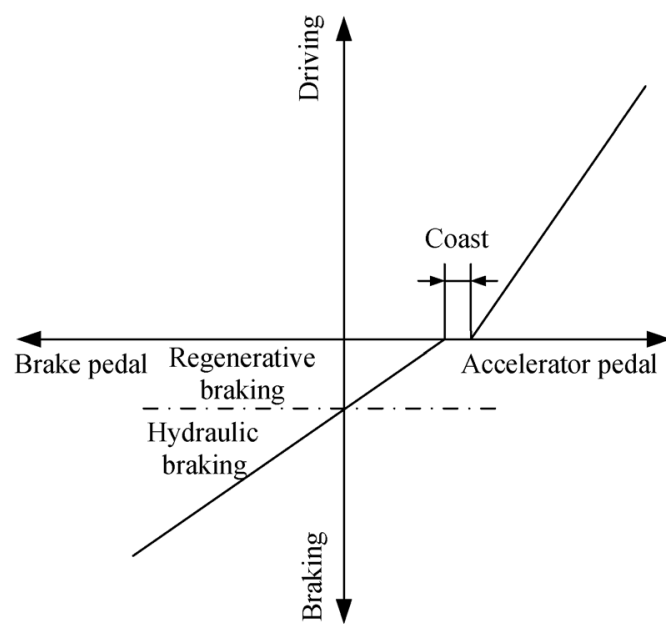

(b)

Fig. 4 Control strategies of different driving modes. (a) Conventional control; (b) single-pedal control. 
Table 1 Single-pedal travel allocation varying with different vehicle velocity (in $\mathrm{km} / \mathrm{h}$ )

\begin{tabular}{|c|c|c|c|c|c|c|c|c|c|c|c|c|c|c|c|}
\hline \multirow{2}{*}{ Pedal travel } & \multicolumn{15}{|c|}{ Driving and braking conditions } \\
\hline & 0 & 1 & 2 & 3 & 4 & 5 & 6 & 7 & 10 & 20 & 40 & 60 & 80 & 100 & 120 \\
\hline $0 \%$ & $\mathrm{C}$ & $\mathrm{R}$ & $\mathrm{R}$ & $\mathrm{R}$ & $\mathrm{R}$ & $\mathrm{R}$ & $\mathrm{R}$ & $\mathrm{R}$ & $\mathrm{R}$ & $\mathrm{R}$ & $\mathrm{R}$ & $\mathrm{R}$ & $\mathrm{R}$ & $\mathrm{R}$ & $\mathrm{R}$ \\
\hline $5 \%$ & $\mathrm{~A}$ & $\mathrm{C}$ & $\mathrm{R}$ & $\mathrm{R}$ & $\mathrm{R}$ & $\mathrm{R}$ & $\mathrm{R}$ & $\mathrm{R}$ & $\mathrm{R}$ & $\mathrm{R}$ & $\mathrm{R}$ & $\mathrm{R}$ & $\mathrm{R}$ & $\mathrm{R}$ & $\mathrm{R}$ \\
\hline $10 \%$ & $\mathrm{~A}$ & $\mathrm{~A}$ & $\mathrm{C}$ & $\mathrm{R}$ & $\mathrm{R}$ & $\mathrm{R}$ & $\mathrm{R}$ & $\mathrm{R}$ & $\mathrm{R}$ & $\mathrm{R}$ & $\mathrm{R}$ & $\mathrm{R}$ & $\mathrm{R}$ & $\mathrm{R}$ & $\mathrm{R}$ \\
\hline $15 \%$ & $\mathrm{~A}$ & $\mathrm{~A}$ & A & $\mathrm{C}$ & $\mathrm{R}$ & $\mathrm{R}$ & $\mathrm{R}$ & $\mathrm{R}$ & $\mathrm{R}$ & $\mathrm{R}$ & $\mathrm{R}$ & $\mathrm{R}$ & $\mathrm{R}$ & $\mathrm{R}$ & $\mathrm{R}$ \\
\hline $20 \%$ & A & A & A & $\mathrm{A}$ & $\mathrm{C}$ & $\mathrm{R}$ & $\mathrm{R}$ & $\mathrm{R}$ & $\mathrm{R}$ & $\mathrm{R}$ & $\mathrm{R}$ & $\mathrm{R}$ & $\mathrm{R}$ & $\mathrm{R}$ & $\mathrm{R}$ \\
\hline $25 \%$ & A & A & A & A & A & $\mathrm{C}$ & $\mathrm{R}$ & $\mathrm{R}$ & $\mathrm{R}$ & $\mathrm{R}$ & $\mathrm{R}$ & $\mathrm{R}$ & $\mathrm{R}$ & $\mathrm{R}$ & $\mathrm{R}$ \\
\hline $30 \%$ & A & A & A & A & A & A & $\mathrm{C}$ & $\mathrm{C}$ & $\mathrm{C}$ & $\mathrm{C}$ & $\mathrm{C}$ & $\mathrm{C}$ & $\mathrm{C}$ & $\mathrm{C}$ & $\mathrm{C}$ \\
\hline $35 \%$ & A & A & A & A & A & A & A & $\mathrm{C}$ & $\mathrm{C}$ & $\mathrm{C}$ & $\mathrm{C}$ & $\mathrm{C}$ & $\mathrm{C}$ & $\mathrm{C}$ & $\mathrm{C}$ \\
\hline $40 \%$ & A & $\mathrm{A}$ & A & $\mathrm{A}$ & A & A & A & A & A & A & $\mathrm{A}$ & A & A & A & A \\
\hline $60 \%$ & $\mathrm{~A}$ & A & A & A & A & A & A & A & A & A & A & A & A & A & A \\
\hline $80 \%$ & A & A & A & A & A & A & A & A & A & A & $\mathrm{A}$ & A & A & A & A \\
\hline Max & A & $\mathrm{A}$ & A & $\mathrm{A}$ & A & A & A & A & A & A & A & A & A & A & A \\
\hline
\end{tabular}

The powertrain linearly outputs drive torque when the accelerator pedal travel is greater than $35 \%$. Each accelerator pedal travel has an acceleration curve.

2) Coasting

No motor torque output is present when the vehicle velocity is greater than $7 \mathrm{~km} / \mathrm{h}$ and the accelerator pedal travel is at the range of $30 \%-35 \%$. The vehicle travels a long distance under the influence of inertia when coasting, which is equal to the vehicle driving at neutral gear. The braking force is zero when coasting. Hence, coasting deceleration $a_{\text {coast }}$ can be denoted as follows:

$$
a_{\text {coast }}=\left(F_{\mathrm{f}}+F_{\mathrm{w}}\right) / m \text {. }
$$

\section{3) Energy recovery}

When deceleration or braking is required, the driver can adjust the accelerator pedal travel to within 0\%-30\% according to road conditions to achieve different regenerative braking strengths. The maximum deceleration is set to $0.2 \mathrm{~g}$, which is achieved when the accelerator pedal travel is $0 \%$. For about every $5 \%$ of pedal travel, deceleration is reduced by $0.03 \mathrm{~g}$. The energy recovery intensity should be reduced from $7 \mathrm{~km} / \mathrm{h}$, and the velocity at which energy recovery is exited completely varies with pedal travel (energy recovery is exited completely at $6 \mathrm{~km} / \mathrm{h}$ when accelerator pedal travel reaches $30 \%$; energy recovery is exited completely at $0 \mathrm{~km} / \mathrm{h}$ when accelerator pedal travel is $0 \%$ ). When the brake pedal is stepped on, the regenerative braking force remains constant, and only mechanical braking force is superimposed. Vehicle decelerations at different accelerator pedal travels vary with velocity, as shown in Fig. 5.

The regenerative braking force of the motor can be derived as follows:

$$
F_{\mathrm{rb}}=F_{\mathrm{d}}-F_{\mathrm{f}}-F_{\mathrm{w}} .
$$

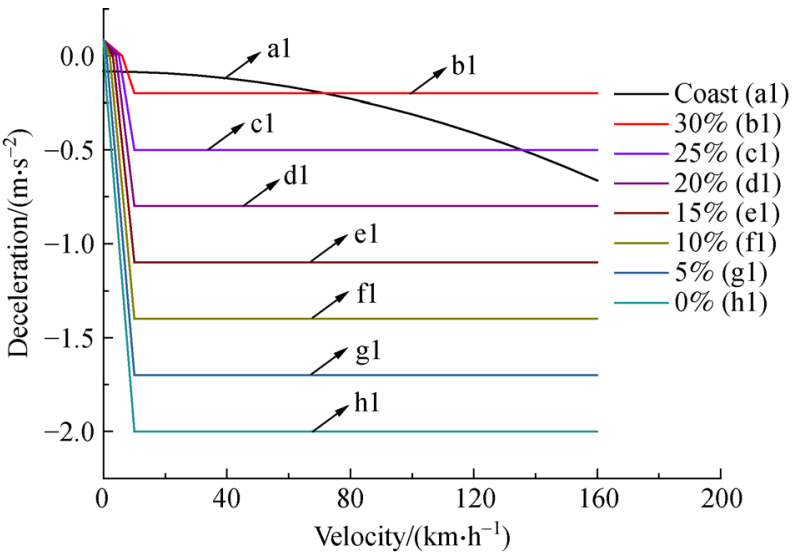

Fig. 5 Vehicle deceleration at different pedal travel.

The deceleration generated by regenerative braking force $a_{\text {regen }}$ can be described as follows:

$$
a_{\mathrm{regen}}=\frac{F_{\mathrm{rb}}}{m}=a-g f-\frac{C_{\mathrm{D}} A \rho u^{2}}{2 m},
$$

where $g$ is gravitational acceleration, $f$ is the rolling resistance coefficient, $C_{\mathrm{D}}$ denotes the drag coefficient, $A$ refers to the windward area, and $\rho$ is the air density.

The vehicle deceleration generated by coasting resistance and regenerative braking force should be constant before the energy recovery starts to exit so that the deceleration generated by the regenerative braking force decreases with the increase in velocity, as shown in Fig. 6.

4) Parking

The vehicle comes to a full stop under regenerative braking force and coasting resistance when the accelerator pedal is completely released. The driver needs to adapt to the single-pedal mode gradually because its coasting 


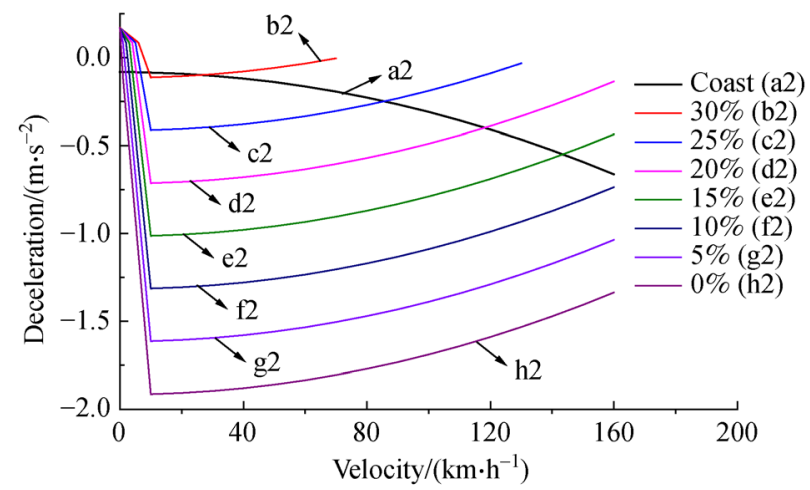

Fig. 6 Deceleration generated by regenerative braking.

distance is much shorter than that of the traditional mode. If necessary, the brake pedal can be stepped on to assist in parking, which is convenient for accurate parking.

\subsection{Control strategy modeling}

A simulation model is built in accordance with the singlepedal control strategy [21]. The inputs are vehicle velocity, battery state of charge (SoC), accelerator pedal travel, and motor speed, and the output is the load signal of motor. Figure 7 demonstrates the model of the single-pedal control strategy. The controller uses an ode4 (RungeKutta) solver with a fixed step. A fixed step size (fundamental sample time) of $0.05 \mathrm{~s}$ is utilized for the simulation.

Figure 8 depicts the single-pedal control flow. The request motor torque is obtained using the look-up table

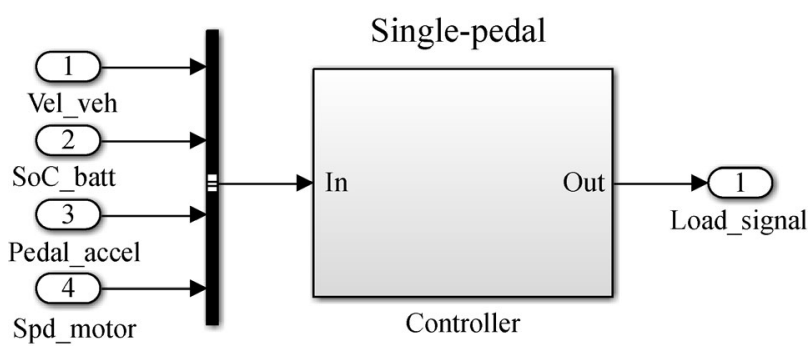

Fig. 7 Single-pedal control strategy model.

method in accordance with vehicle velocity and accelerator pedal travel. The maximum motor torque is obtained based on motor speed, and the maximum charging power is derived based on battery SoC. The request torque is further modified after considering the abovementioned limitations. Then, the vehicle is driven or the brakes are applied under the action of the resultant force. Simulink is used to calculate the torque demand, and the vehicle dynamic process is simulated with Cruise.

\section{Simulation and evaluation}

\subsection{Performance evaluation index}

Indexes must be set to evaluate the performance of regenerative braking. Braking efficiency and energy recovery effects are used to evaluate regenerative braking performance under single-pedal control [22-24].

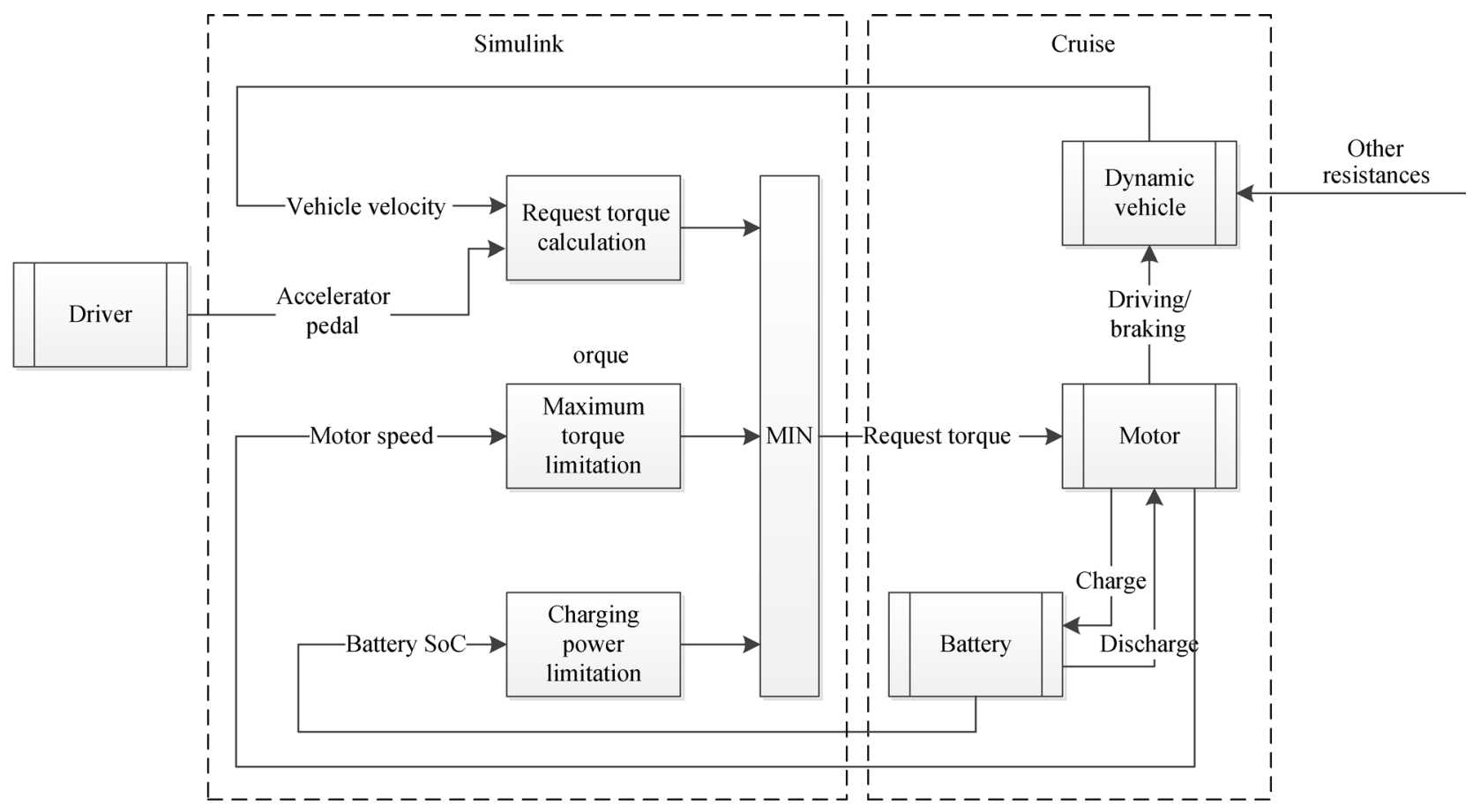

Fig. 8 Flowchart of single-pedal control. MIN: Minimum. 


\subsubsection{Braking efficiency}

The most basic evaluation index of braking performance is braking efficiency, which refers to the braking distance or deceleration while the vehicle brakes on a flat road at a certain initial velocity [25].

1) Braking deceleration

Braking deceleration reflects the amount of ground braking force. Instantaneous deceleration is complicated and changeable. Hence, the automotive industry uses average deceleration $\bar{a}$, which is calculated as follows:

$$
\bar{a}=\frac{1}{t_{2}-t_{1}} \int_{t_{1}}^{t_{2}} a(t) \mathrm{d} t,
$$

where $t_{1}$ is the time at which the brake pressure reaches $75 \%$ of the maximum pressure and $t_{2}$ is $2 / 3$ of the brake ending time.

2) Braking distance

Braking distance pertains to the distance from when the brake pedal is stepped on initially to the moment when the vehicle comes to a complete stop. It consists of the distances that the vehicle has traveled during two phases, namely, brake response and continuous braking.

$$
s=s_{1}+s_{2}=u_{0}\left(\tau_{1}^{\prime}+\frac{\tau_{1}^{\prime \prime}}{2}\right)+\frac{u_{0}^{2}}{2 a_{\mathrm{bmax}}}-\frac{a_{\mathrm{bmax}} \tau_{1}^{\prime \prime 2}}{24},
$$

where $\tau_{1}^{\prime}$ is the brake response time, $\tau_{1}^{\prime \prime}$ is the continuous braking time, $s_{1}$ is the braking distance at brake response time, $s_{2}$ is the braking distance at continuous braking time, and $a_{\mathrm{bmax}}$ refers to the maximum braking deceleration.

\subsubsection{Energy recovery effect}

The ultimate goal of this study on the single-pedal control strategy is to improve the energy recovery rate and extend the driving range of EVs [26]. Energy recovery rate and driving range are selected as evaluation indexes to analyze the energy recovery effect.

1) Energy recovery rate

Energy recovery rate $\eta_{\mathrm{r}}$ is the ratio of energy recovered in braking process to the energy consumed in the entire driving cycle.

$$
\eta_{\mathrm{r}}=\frac{E_{\mathrm{rb}}}{E_{\mathrm{b}}+E_{\mathrm{k}}},
$$

where $E_{\mathrm{k}}$ and $E_{\mathrm{b}}$ are the energy consumed by driving and braking, respectively.

2) Driving range

Driving range $L$ is the distance that $\mathrm{EVs}$ are able to drive from full charge until the battery runs out.

$$
L=\frac{E_{1}+E_{2}}{W} S_{\text {cycle }},
$$

where $E_{1}$ and $E_{2}$ denote the initial energy of the battery and energy recovered by the regenerative braking system, respectively, $W$ is the energy consumed by the entire driving cycle, and $S_{\text {cycle }}$ is the range of a single driving cycle.

\subsection{Co-simulation}

The vehicle simulation model is built according to the construction of EVs. Forward simulation is similar to the actual driving state and can reflect the dynamic performance of each component. Forward simulation has high precision and is suitable for the analysis of the control strategy [27]. Tables 2 and 3 provide the basic parameters of the vehicle and the performance parameters of the powertrain, respectively.

Table 2 Basic parameters of the vehicle

\begin{tabular}{lc}
\hline Parameter & Value \\
\hline Length $\times$ width $\times$ height $) / \mathrm{mm}$ & $4337 \times 1825 \times 1637$ \\
Wheelbase $/ \mathrm{mm}$ & 2560 \\
Curb mass $m / \mathrm{kg}$ & 1667 \\
Rolling resistance coefficient $f$ & 0.008 \\
Windward $A / \mathrm{m}^{2}$ & 2.54 \\
Final ratio $i_{0}$ & 9.07 \\
Wind resistance coefficient $C_{\mathrm{D}}$ & 0.32 \\
Tire specification & $215 / 55 \mathrm{R} 18$
\end{tabular}

Table 3 Performance parameters of the powertrain

\begin{tabular}{lcc}
\hline Component & Parameter & Value \\
\hline Battery & Capacity $/(\mathrm{kW} \cdot \mathrm{h})$ & 52 \\
& Nominal voltage $/ \mathrm{V}$ & 350 \\
& SoC working range & $5 \%-95 \%$ \\
Motor & Rated and peak speed $/\left(\mathrm{r} \cdot \mathrm{min}^{-1}\right)$ & 4340,12000 \\
& Rated and peak power $/ \mathrm{kW}$ & 50,120 \\
\multirow{2}{*}{ Auxiliary } & Rated and peak torque $/(\mathrm{N} \cdot \mathrm{m})$ & 110,240 \\
\hline
\end{tabular}

The single-pedal control strategy is embedded into the vehicle simulation model in the form of a Matlab DLL module, and conventional brake conditions and urban driving cycles are selected for co-simulation. Figure 9 displays the simulation model. The accelerator pedal signal is outputted from the cockpit and processed by the control strategy. Then, the load signal of the motor is outputted. The power passes through the battery, motor, and powertrain (including the final drive, gearbox, and differential) in turn and finally reaches the wheel. 


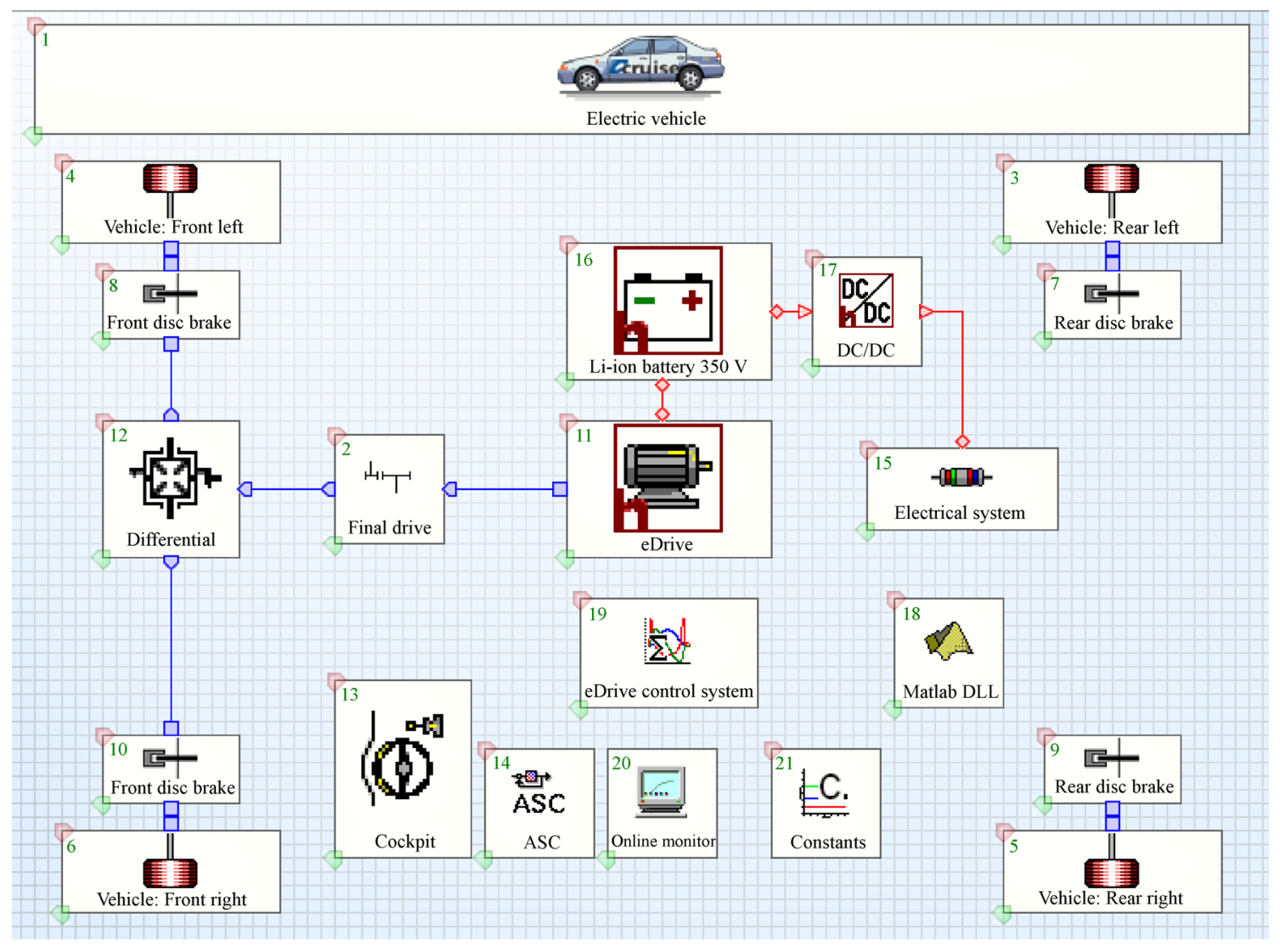

Fig. 9 Vehicle simulation model.

\subsubsection{Conventional brake conditions}

Safety should be ensured when braking at different velocities and braking strengths [28]. In accordance with urban traffic conditions, initial braking velocities of 30 and $60 \mathrm{~km} / \mathrm{h}$ are selected. The accelerator pedal is fully released at the initial braking velocity. Figures 10 and 11 provide the simulation results. Braking deceleration meets the braking requirements, and the braking distance meets the safety requirements. When the vehicle velocity is higher than $7 \mathrm{~km} / \mathrm{h}$, the regenerative braking torque of the motor gradually increases with the decrease in vehicle velocity. However, when the vehicle velocity is lower than $7 \mathrm{~km} / \mathrm{h}$, the regenerative braking torque of the motor rapidly decreases to zero with the decrease in vehicle velocity. The braking process is consistent with the singlepedal control strategy.

Table 4 shows the energy recovery when braking at initial vehicle velocities of 30 and $60 \mathrm{~km} / \mathrm{h}$. The higher the velocity is, the larger the recovered energy is and the higher the energy recovery efficiency is.

\subsubsection{Urban driving cycle}

Simulation under driving cycles can fully reflect the energy recovery during the actual driving of EVs [29]. Velocity is low and braking is frequent when vehicles are driving in urban areas with serious traffic congestion. Therefore, the energy recovery in urban driving cycles is better than that in high-speed conditions. New European Driving Cycle (NEDC) is the most representative urban driving cycle. Vehicle fuel consumption identified by the Ministry of Industry and Information Technology of China is obtained via testing under NEDC. By contrast, the Worldwide Harmonized Light Vehicles Test Cycle (WLTC) has a longer test period and higher average velocity than NEDC, and it is highly similar to actual driving situations. Its wider velocity range is more stringent for vehicle performance. WLTC will become the national standard driving cycle for energy consumption testing of EVs in the near future. For these reasons, NEDC and WLTC are selected for the simulation to verify the single-pedal control strategy.

Simulations are conducted in a single driving cycle at an initial battery $\mathrm{SoC}$ of $95 \%$ (Figs. 12 and 13). The velocity simulation results are shown in Figs. 12(a) and 13(a). The actual velocity follows the target velocity well, which indicates that the simulation model is reliable. Figures 12(b) and 13(b) show the motor responses to the driving cycle, where the driving and braking torques are positive and negative, respectively. The simulation results show that driving and braking can be achieved by the single pedal, which indicates that the single-pedal control 


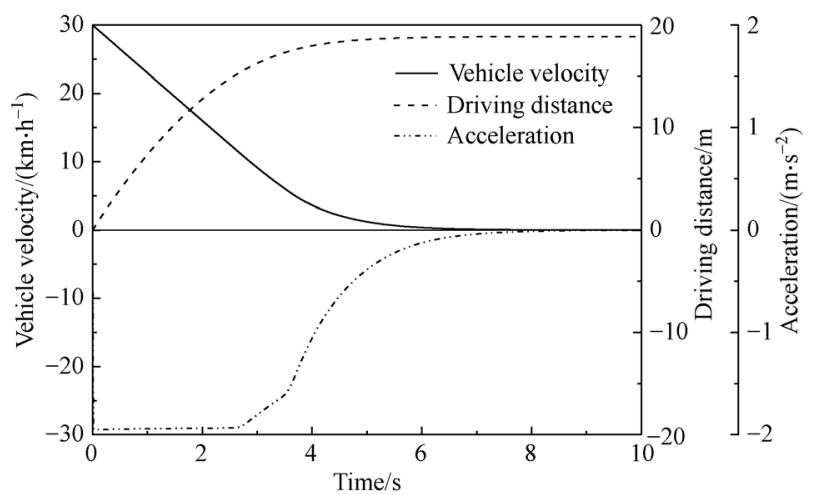

(a)

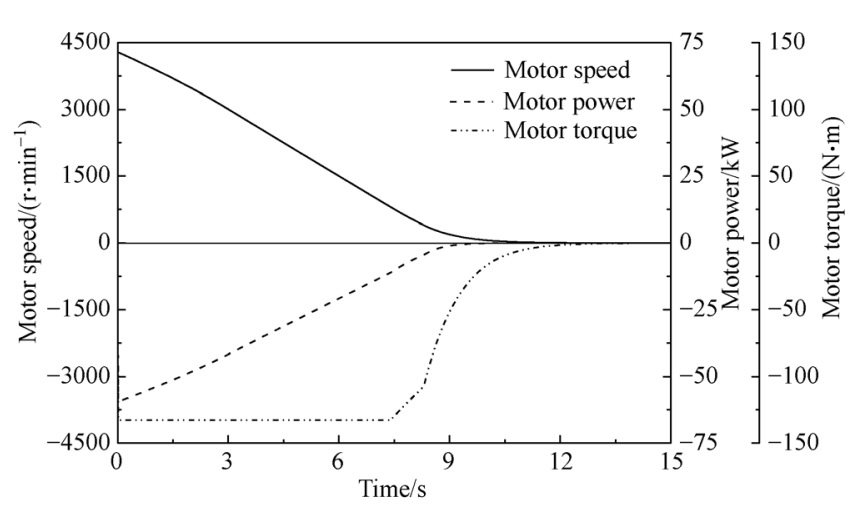

(b)

Fig. 10 Simulation results of conventional braking $(30 \mathrm{~km} / \mathrm{h})$. (a) Vehicle simulation result; (b) motor simulation result.

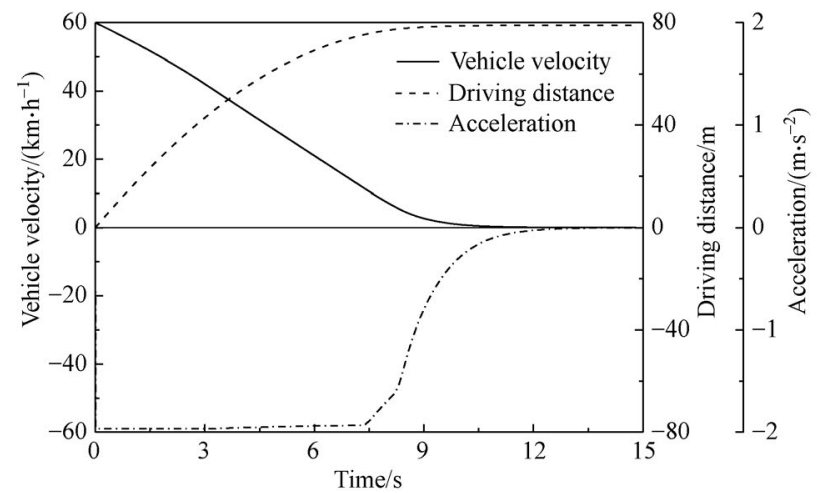

(a)

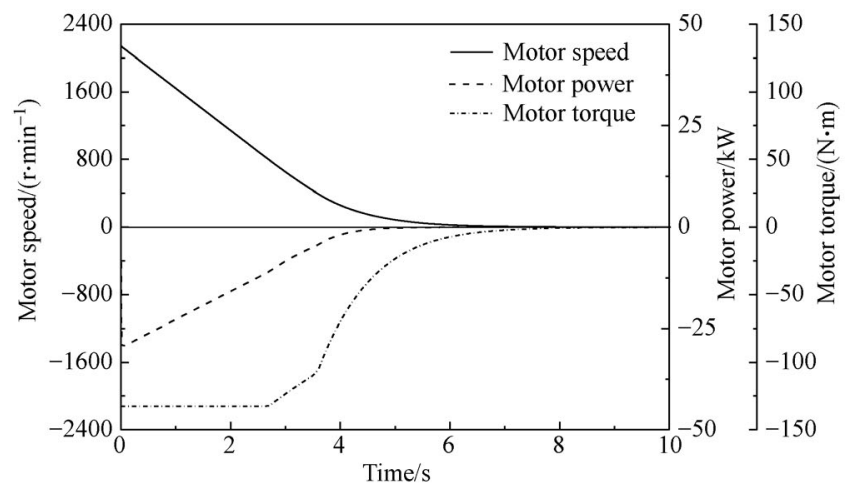

(b)

Fig. 11 Simulation results of conventional braking $(60 \mathrm{~km} / \mathrm{h})$. (a) Vehicle simulation result; (b) motor simulation result.

Table 4 Regenerative braking simulation under conventional braking conditions

\begin{tabular}{lccc}
\hline Initial braking velocity $/\left(\mathrm{km} \cdot \mathrm{h}^{-1}\right)$ & Braking energy $/ \mathrm{kJ}$ & Recovered energy $/ \mathrm{kJ}$ & Energy recovery efficiency \\
\hline 30 & 64.97 & 51.98 & $80.01 \%$ \\
60 & 251.45 & 218.70 & $86.98 \%$ \\
\hline
\end{tabular}

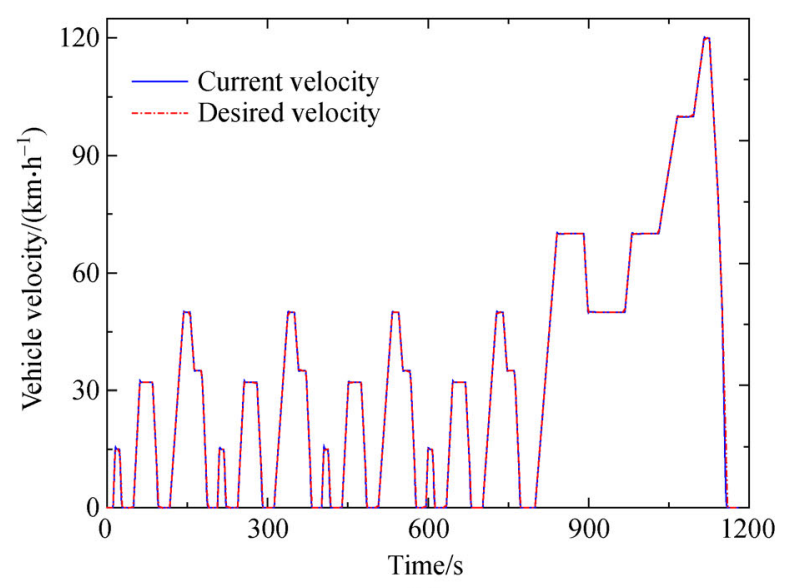

(a)

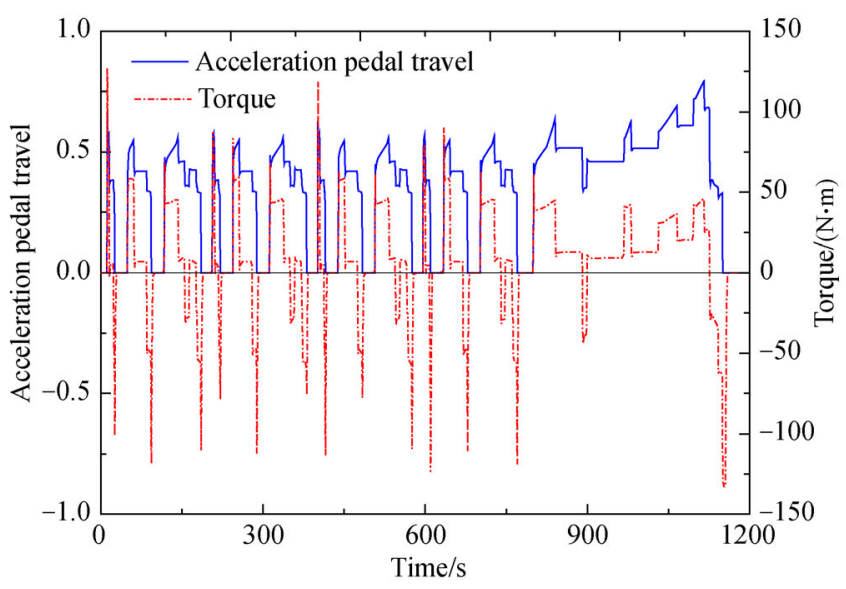

(b)

Fig. 12 Simulation results under NEDC. (a) Vehicle simulation result; (b) motor simulation result. 


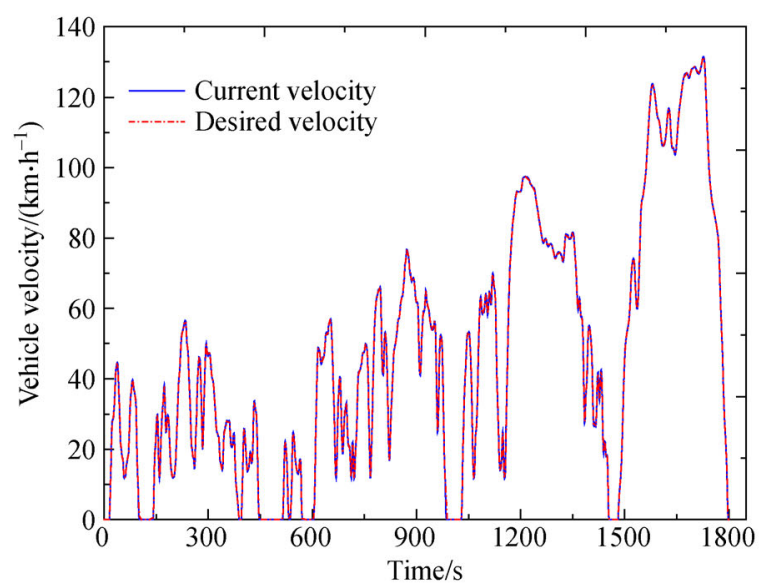

(a)

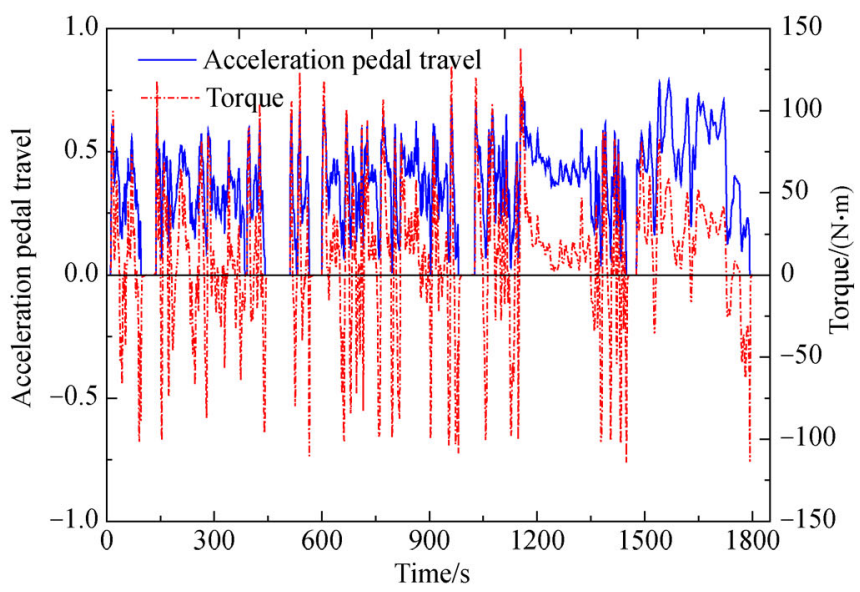

(b)

Fig. 13 Simulation results under WLTC. (a) Vehicle simulation result; (b) motor simulation result.

strategy is effective.

Simulations are conducted in a single driving cycle at an initial battery $\mathrm{SoC}$ of $95 \%$. Figure 14 presents the variations in battery SoC with driving cycles under

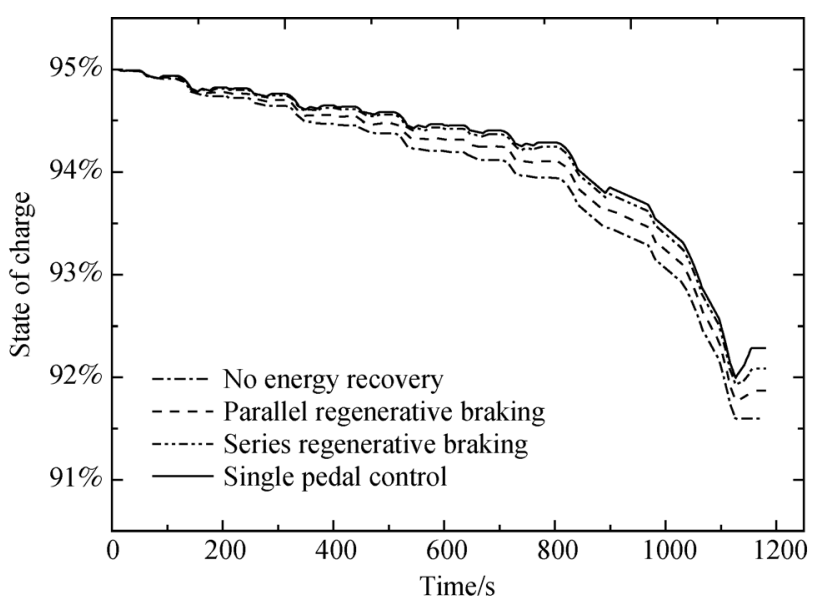

(a)

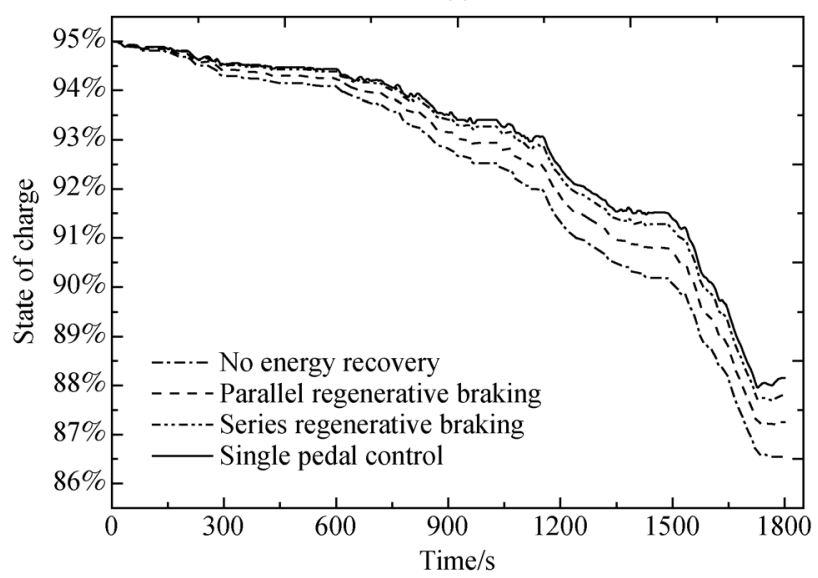

(b)

Fig. 14 Battery simulation results using various control strategies. Changes in battery SoC under (a) NEDC and (b) WLTC. different control strategies. The rise represents brake and charge, and the descent represents drive and discharge. The slope represents the rate of charge and discharge. The battery SoC of EVs equipped with the single-pedal control system displays the slowest declines and remains the highest at the end of the simulation. This finding indicates that energy consumed in the entire driving cycle is minimal, and the vehicle economy is optimal.

Simulations are conducted under driving cycles starting with a battery SoC of $95 \%$ and ending with a battery SoC of $5 \%$.

Table 5 provides the simulation results obtained by using different control strategies under NEDC. The driving range of EVs with the single-pedal control system is extended by $63.29 \mathrm{~km}$. The energy recovery rate of single-pedal control is as high as $26.12 \%$, which is $152.12 \%$ and $40.20 \%$ higher than that of parallel regenerative braking and series regenerative braking, respectively.

Table 6 depicts the simulation results obtained using different control strategies under WLTC. The driving range of the EV with the single-pedal control system is extended by $51.72 \mathrm{~km}$. The energy recovery rate of single-pedal control is as high as $20.77 \%$, which is $137.10 \%$ and $35.31 \%$ higher than that of parallel regenerative braking and series regenerative braking, respectively.

The energy recovery of single-pedal control, including traditional regenerative braking, enables EVs with the single-pedal control system to have a higher energy recovery rate, lower electricity consumption, longer driving range, and better power economy than EVs without such a system.

\section{Dynamometer test}

A chassis dynamometer provides reverse torque, and it serves as the driving resistance for the simulation. The 
Table 5 Comparison of energy recovery using different control strategies under NEDC

\begin{tabular}{lcccc}
\hline Control strategy & Driving range/km & Total energy consumption/kJ & Recovered energy/kJ & Recovery rate \\
\hline No RBS & 256.32 & 126497 & - & - \\
Parallel & 279.24 & 137699 & 14259 & $10.36 \%$ \\
Series & 299.23 & 148014 & 27576 & $18.63 \%$ \\
Single-pedal & 319.61 & 158269 & 41340 & $26.12 \%$ \\
\hline
\end{tabular}

Table 6 Comparison of energy recovery using different control strategies under WLTC

\begin{tabular}{lcccc}
\hline Control strategy & Driving range/km & Total energy consumption/kJ & Recovered energy/kJ & Recovery rate \\
\hline No RBS & 220.71 & 156628 & - & - \\
Parallel & 241.60 & 171095 & 14994 & $8.76 \%$ \\
Series & 259.04 & 183809 & 28206 & $15.35 \%$ \\
Single-pedal & 272.43 & 195275 & 40554 & $20.77 \%$ \\
\hline
\end{tabular}

dynamometer test is controlled by a computer and a programmable controller [30,31]. Various devices are used to collect and analyze vehicle dynamic performance.

\subsection{Test conditions and preparation}

\section{1) Environment}

The test environment affects the test results. Hence, the following conditions should be met: temperature between $0{ }^{\circ} \mathrm{C}$ and $40{ }^{\circ} \mathrm{C}$, humidity less than $85 \%$, and air pressure between 80 and $110 \mathrm{MPa}$.

2) Equipment

The following equipment are required for the test: EV, computer, data acquisition equipment CANalyzer, and chassis dynamometer.

3) Tester preparation

The chassis dynamometer should meet inspection standards. Before testing, the moving parts should be inspected and debugged according to the instruction manual to ensure that they are in good condition. The chassis dynamometer should be driven by the test vehicle for 10 to $30 \mathrm{~min}$ so that the moving parts reach the normal operating temperature.

4) Vehicle preparation

The test vehicle should meet the manufacturer's technical standards. Before testing, each component should be inspected thoroughly to ensure safety. The test vehicle should be preheated for $5 \mathrm{~min}$ to reach the normal operating temperature, and the single-pedal control strategy should be burned into the VCU.

\subsection{Test and result analysis}

Vehicle with single-pedal control system is simulated under NEDC using the chassis dynamometer, and the CANalyzer is used to collect the test data. Vehicle dynamic information is displayed and played back in real time on the computer. Figures 15 and 16 show the dynamometer test and data acquisition, respectively.

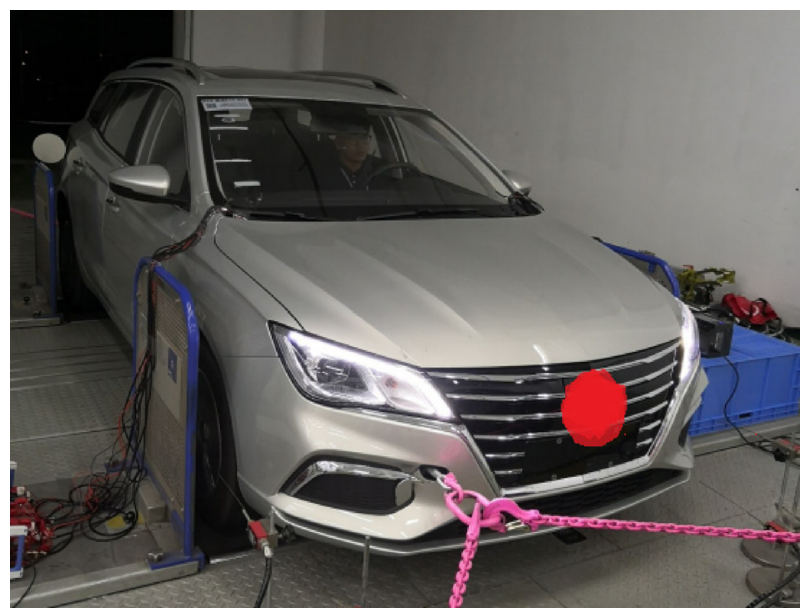

Fig. 15 Dynamometer test.

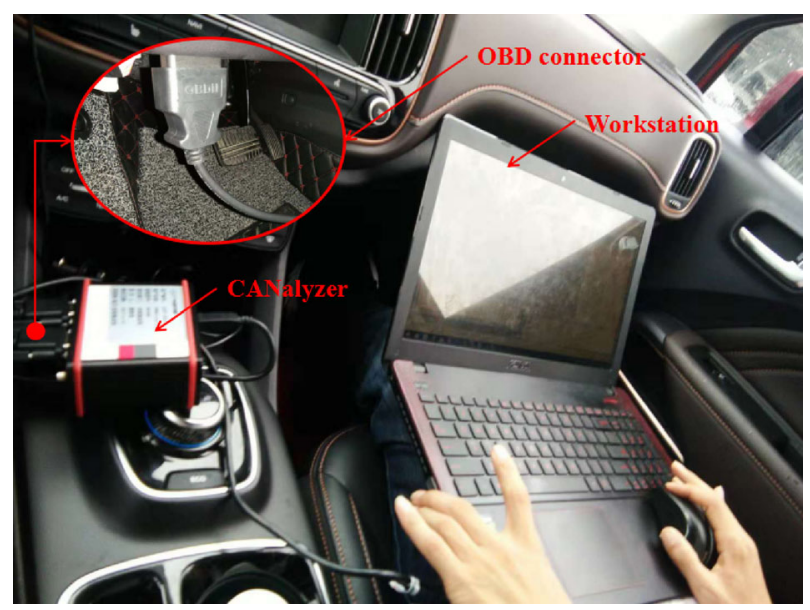

Fig. 16 Test data acquisition. 
Figure 17 presents the dynamometer test results, which include the accelerator pedal travel, vehicle velocity, and motor torque. When the accelerator pedal is stepped on, positive motor torque is outputted to drive the vehicle. When the accelerator pedal is released, the motor torque quickly changes from positive to negative, and the negative regenerative braking torque decelerates the vehicle. The shape of the accelerator pedal travel signal is nearly identical to that of the motor torque signal, indicating that the motor can respond accurately and rapidly. The vehicle velocity signal lags behind the motor torque signal due to the torque transmission and vehicle response.

Table 7 provides the dynamometer test data on driving range and energy recovery. Unlike in the simulation results, the driving range is reduced by $7.58 \mathrm{~km}(2.37 \%)$, and the braking energy recovery rate is reduced by $0.48 \%$ $(1.84 \%)$. However, both results are within the allowable error range $(5 \%)$. Comparison of the simulation results with the test data indicates that the developed single-pedal simulation model is reliable, and the proposed single-pedal control strategy is effective.

\section{Conclusions}

A single-pedal control strategy is proposed to improve the energy recovery rate and extend the driving range of EVs. The energy recovery capability is analyzed theoretically according to the construction of the single-pedal system, vehicle braking dynamics, and law of energy conservation. The single-pedal control strategy is developed based on daily driving situations, and a single-pedal simulation model is established. Conventional braking conditions and urban driving cycles are selected for the simulation, and a dynamometer test is conducted for verification. After analyzing the simulation results and test data, the following conclusions are obtained.

1) Conventional braking conditions are selected for the simulation of braking performance. The simulation results show that the braking deceleration of the EV with the single-pedal control system meets the vehicle braking requirements, and the braking distance meets braking safety regulations. Vehicle safety can be guaranteed under single-pedal control.

2) Urban driving cycles are selected for the simulation of energy recovery. The simulation results under NEDC and WLTC show that the energy recovery rates are as high as $26.12 \%$ and $20.77 \%$, and the driving ranges are extended by 63.29 and $51.72 \mathrm{~km}$, respectively. The application of the single-pedal control system to EVs can effectively improve the energy recovery rate and extend the driving range.

3) A dynamometer test is conducted under NEDC. The comparison of the test data and simulation results shows

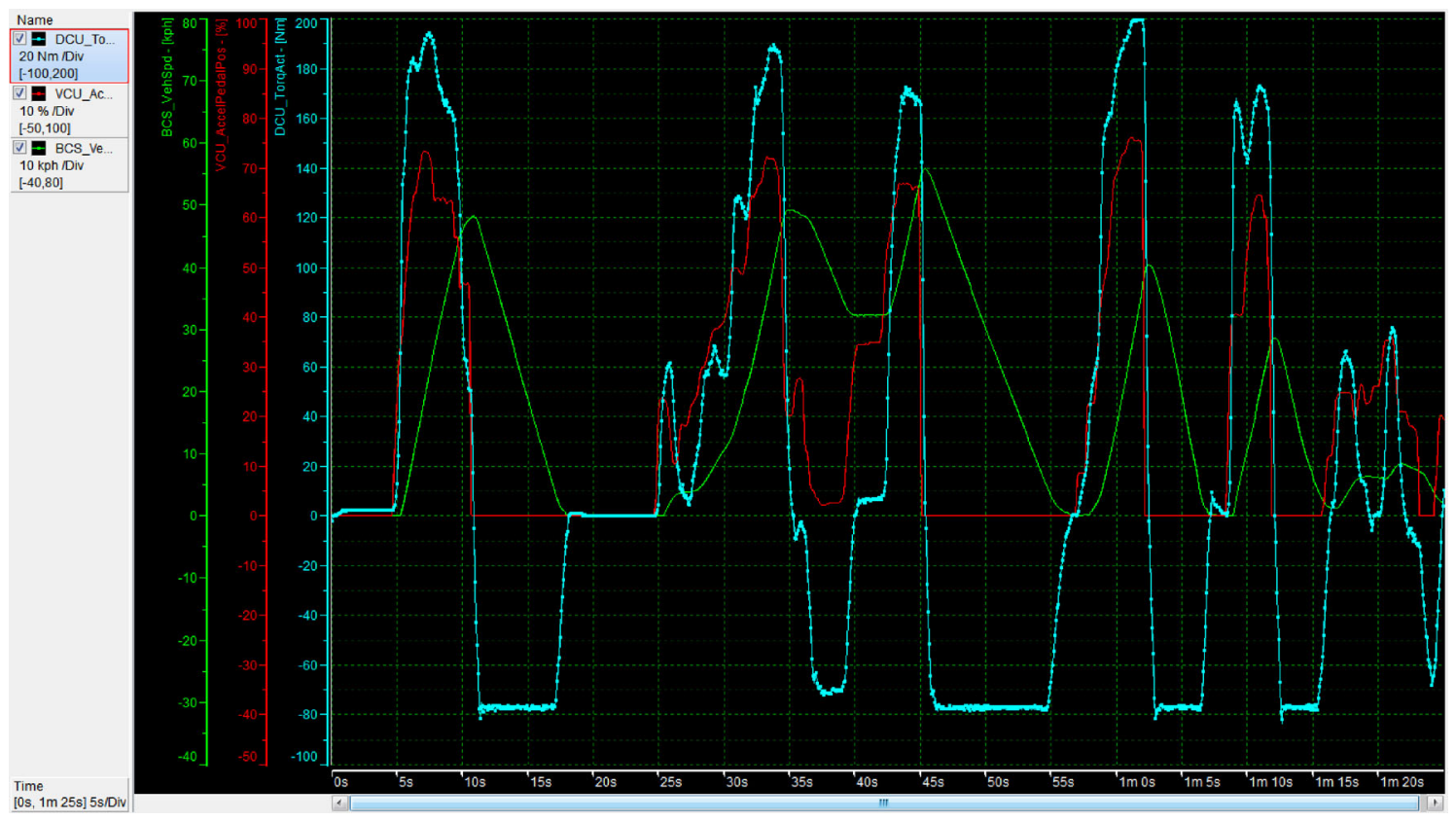

Fig. 17 Results of the dynamometer test.

Table 7 Comparison of simulation and test data on energy recovery

\begin{tabular}{lcccc}
\hline NEDC & Driving range/km & Consumed energy/kJ & Recovered energy/kJ & Energy recovery rate \\
\hline Simulation & 319.61 & 158269 & 41340 & $26.12 \%$ \\
Test & 312.03 & 158812 & 40722 & $25.64 \%$ \\
\hline
\end{tabular}


that the driving range is reduced by $7.58 \mathrm{~km}$, and energy recovery rate is reduced by $0.48 \%$. Both values are within the allowable error range, which verifies the effectiveness of the single-pedal control strategy and the reliability of the simulation model. The test is specifically prepared for engineering applications of the single-pedal control system.

In future studies, advanced control theories, such as neural networks and group intelligence algorithms, could be applied to the energy recovery control strategy. Adaptive learning of driving habits and automatic recognition of braking intentions could be achieved. Thus, driving and braking could be controlled with increased coordination.

Acknowledgements This work was supported by the National Natural Science Foundation of China (Grant No. 51675324).

Open Access This article is licensed under a Creative Commons Attribution 4.0 International License, which permits use, sharing, adaptation, distribution and reproduction in any medium or format, as long as you give appropriate credit to the original author(s) and the source, provide a link to the Creative Commons licence, and indicate if changes were made.

The images or other third party material in this article are included in the article's Creative Commons licence, unless indicated otherwise in a credit line to the material. If material is not included in the article's Creative Commons licence and your intended use is not permitted by statutory regulation or exceeds the permitted use, you will need to obtain permission directly from the copyright holder.

To view a copy of this licence, visit http://creativecommons.org/licenses/ by $/ 4.0 \%$.

\section{References}

1. Barkenbus J. Electric vehicles: Climate saviors, or not? Issues in Science and Technology, 2017, 33: 55-59

2. Wang Z Q, Chen W. Confidence-based adaptive extreme response surface for time-variant reliability analysis under random excitation. Structural Safety, 2017, 64: 76-86

3. Zhang J Z, Lv C, Gou J F, et al. Cooperative control of regenerative braking and hydraulic braking of an electrified passenger car. Proceedings of the Institution of Mechanical Engineers, Part D: Journal of Automobile Engineering, 2012, 226(10): 1289-1302

4. Qiu C K, Wang G L. New evaluation methodology of regenerative braking contribution to energy efficiency improvement of electric vehicles. Energy Conversion and Management, 2016, 119: 389-398

5. Kumar M S, Revankar S T. Development scheme and key technology of an electric vehicle: An overview. Renewable and Sustainable Energy Reviews, 2017, 70: 1266-1285

6. Bildstein M, Mann K, Richter B. Regenerative braking system. In: Reif K, ed. Fundamentals of Automotive and Engine Technology. Wiesbaden: Springer Vieweg, 2014, 240-243

7. $\mathrm{Xu} \mathrm{G}, \mathrm{Xu} \mathrm{K}$, Zheng $\mathrm{C}$, et al. Fully electrified regenerative braking control for deep energy recovery and maintaining safety of electric vehicles. IEEE Transactions on Vehicular Technology, 2016, 65(3): 1186-1198
8. Bunyaeva E V, Skorik V G, Vlas'Evskii S V, et al. A method for improving the energy efficiency of an alternating current electric locomotive in the regenerative braking mode. Russian Electrical Engineering, 2016, 87(2): 73-76

9. Yu J W, Zheng S L, Pham H, et al. Reliability modeling of multistate degraded repairable systems and its applications to automotive systems. Quality and Reliability Engineering International, 2018, 34(3): 459-474

10. Lv C, Hu X S, Sangiovanni-Vincentelli A, et al. Driving-style-based co-design optimization of an automated electric vehicle: A cyberphysical system approach. IEEE Transactions on Industrial Electronics, 2019, 66(4): 2965-2975

11. Wu J N, Yan S Z, Zuo M J. Evaluating the reliability of multi-body mechanisms: A method considering the uncertainties of dynamic performance. Reliability Engineering \& System Safety, 2016, 149: 96-106

12. Zeff S. My electric journey with a Nissan Leaf: A classic earlyadopter experience. IEEE Consumer Electronics Magazine, 2016, 5(3): 79-80

13. Tie S F, Tan C W. A review of energy sources and energy management system in electric vehicles. Renewable and Sustainable Energy Reviews, 2013, 20: 82-102

14. Lv C, Zhang J Z, Li Y T, et al. Mechanism analysis and evaluation methodology of regenerative braking contribution to energy efficiency improvement of electrified vehicles. Energy Conversion and Management, 2015, 92: 469-482

15. Dong Q C, Liu X T, Qi H Z, et al. Analysis and evaluation of electromagnetic vibration and noise in permanent magnet synchronous motor with rotor step skewing. Science China Technological Sciences, 2019, 62(5): 839-848

16. Shang Z Z, Qi H Z, Liu X T, et al. Structural optimization of lithiumion battery for improving thermal performance based on a liquid cooling system. International Journal of Heat and Mass Transfer, 2019, 130: 33-41

17. Ehsani M, Gao Y M, Emadi A. Modern Electric, Hybrid Electric, and Fuel Cell Vehicles: Fundamentals, Theory, and Design. 2nd ed. Abingdon: Taylor \& Francis Group, 2010, 90

18. Bravo R R S, De Negri V J, Oliveira A A M. Design and analysis of a parallel hydraulic-pneumatic regenerative braking system for heavy-duty hybrid vehicles. Applied Energy, 2018, 225: 60-77

19. Zhao D, Chu L, Xu N, et al. Development of a cooperative braking system for front-wheel drive electric vehicles. Energies, 2018, 11(2): 378

20. Kumar C N, Subramanian S C. Cooperative control of regenerative braking and friction braking for a hybrid electric vehicle. Proceedings of the Institution of Mechanical Engineers, Part D: Journal of Automobile Engineering, 2016, 230(1): 103-116

21. Ko J W, Ko S Y, Kim I S, et al. Co-operative control for regenerative braking and friction braking to increase energy recovery without wheel lock. International Journal of Automotive Technology, 2014, 15(2): 253-262

22. Liang C, Cai J W, Fu Z C, et al. Research on brake energy regeneration evaluation and test method of pure electric vehicle. Journal of Huazhong University of Science and Technology (Natural Science Edition), 2014, 42: 18-22 (in Chinese)

23. Alvarez R, López A, De la Torre N. Evaluating the effect of a 
driver's behaviour on the range of a battery electric vehicle. Proceedings of the Institution of Mechanical Engineers, Part D, Journal of Automobile Engineering, 2015, 229(10): 1379-1391

24. Liu L, Liu X T, Wang X L, et al. Reliability analysis and evaluation of a brake system based on competing risks. Journal of Engineering Research, 2017, 5(3): 150-161

25. Xu B, Cheng M, Yang H Y, et al. Safety brake performance evaluation and optimization of hydraulic lifting systems in case of overspeed dropping. Mechatronics, 2013, 23(8): 1180-1190

26. Shafie-khah M, Heydarian-Forushani E, Golshan M E H, et al. Optimal trading of plug-in electric vehicle aggregation agents in a market environment for sustainability. Applied Energy, 2016, 162: 601-612

27. Xiao P, Lou J, Niu L M, et al. Modeling and simulation of regenerative braking performance of electric vehicles based on decoupling strategy. Key Engineering Materials, 2016, 693: 16671675

28. Oleksowicz S A, Burnham K J, Southgate A, et al. Regenerative braking strategies, vehicle safety and stability control systems: Critical use-case proposals. Vehicle System Dynamics, 2013, 51(5): 684-699

29. Yang Y J. A study on the control strategy for maximum energy recovery by regenerative braking in electric vehicles. Automotive Engineering, 2013, 35(2): 105-110 (in Chinese)

30. Zhang J M, Cui S S, Ren Y C. Modeling and simulation of PHEV regenerative braking test platform. Advanced Materials Research, 2011, 219-220: 1170-1173

31. Liu X T, Zheng S L, Tie C, et al. Durability testing method of a hubreducer system based on the Shanghai standard road driving cycle. Journal of Testing and Evaluation, 2016, 44(1): 665-678 